Derecho arbitral 


\section{Algunos apuntes sobre la Convención de Nueva York: causales de denegación}

\section{Gonzalo García Calderón Moreyra}

\section{Introducción}

La finalidad de todo reconocimiento está en darle fuerza jurídica obligatoria, en un Estado, a un fallo emanado de o dictado en otro, fallo que, por el principio de territorialidad, no podría ser ejecutado en un país distinto de aquel en que se originó.

El exequatur es, en suma, el pase que el juez competente, en el país de la solicitud de reconocimiento, concede a una sentencia que proviene de otro ordenamiento jurídico, con el fin de darle las características y la fuerza de una sentencia nacional luego de cumplir con los requisitos que cada legislación exige.

Como dice Gaetano Morelli: “La sentencia extranjera antes del juicio de reconocimiento es un hecho jurídico cuya eficacia se encuentra en un estado de dependencia, como subordinado a un evento futuro (conditio iuris) constituido por la sentencia de reconocimiento".

\section{Convención de Nueva York, aprobada el 10 de junio de $\mathbf{1 9 5 8}$}

Esta convención ha permitido el desarrollo del arbitraje al unificar criterios, homologando procedimientos y requisitos para el reconocimiento de laudos o sentencias arbitrales que han sido dictadas 
en Estados diferentes de aquel en que se pide su reconocimiento y ejecución.

Se trata de una convención que en la actualidad cuenta con 146 Estados partes y que integra nuestro ordenamiento jurídico desde su ratificación por el Perú, el 7 de julio de 1988, y su entrada en vigencia, el 5 de octubre del mismo año. La actual Ley de Arbitraje (Decreto Legislativo 1071, publicado el 28 de junio del 2008) expresa en su artículo 74:

Son laudos extranjeros los pronunciados en un lugar que se halle fuera del territorio peruano. Serán reconocidos y ejecutados en el Perú de conformidad con los siguientes instrumentos, teniendo en cuenta los plazos de prescripción previstos en el derecho peruano:

a. La Convención sobre el Reconocimiento y Ejecución de Sentencias Arbitrales Extranjeras, aprobada en Nueva York el 10 de junio de 1958, o

b. La Convención Interamericana de Arbitraje Comercial Internacional, aprobada en Panamá el 30 de enero de 1975, o

c. Cualquier otro tratado sobre reconocimiento y ejecución de laudos arbitrales del cual sea parte el Perú.

Salvo que las partes hayan acordado algo distinto, el tratado aplicable será el más favorable a la parte que solicite el reconocimiento y ejecución de un laudo extranjero.

No debe olvidarse que la Convención de Nueva York tuvo como objetivo principal facilitar o favorecer la circulación internacional de los laudos; así, a pesar de contar con solo dieciséis artículos, su contenido no escrito tiene una riqueza que vale la pena resaltar.

Mantilla-Serrano (2009) indica:

En consecuencia, todo laudo dictado fuera del territorio del Estado donde se pide su ejecución o reconocimiento se beneficiará de la Convención (independientemente de que ese laudo haya sido dictado dentro del marco de un arbitraje interno o internacional). La internacionalidad del arbitraje es una cuestión que compete decidir al 
ordenamiento jurídico del lugar del arbitraje y es determinante, por lo esencial, para conocer la esfera (nacional o internacional) de la actuación de los árbitros y, a la luz de ello, decidir cuestiones sobre el procedimiento a seguir y sobre la aplicación a dicho arbitraje de las disposiciones internas existentes en materia de arbitraje.

\section{Causales de denegación ${ }^{1}$}

Dentro de las causales para denegar el reconocimiento y ejecución de las sentencias o laudos arbitrales regulados en la Convención de Nueva

1 Artículo V:

1. Solo se podrá denegar el reconocimiento y la ejecución de la sentencia, a instancia de la parte contra la cual es invocada, si esta parte prueba ante la autoridad competente del país en que se pide el reconocimiento y la ejecución:

a) Que las partes en el acuerdo a que se refiere el artículo II estaban sujetas a alguna incapacidad en virtud de la ley que es aplicable o que dicho acuerdo no es válido en virtud de la ley a que las partes lo han sometido, o si nada se hubiera indicado a este respecto, en virtud de la ley del país en que se haya dictado la sentencia; o

b) Que la parte contra la cual se invoca la sentencia arbitral no ha sido debidamente notificada de la designación del árbitro o del procedimiento de arbitraje o no ha podido, por cualquier otra razón, hacer valer sus medios de defensa; o

c) Que la sentencia se refiere a una diferencia no prevista en el compromiso o no comprendida en las disposiciones de la cláusula compromisoria, o contiene decisiones que exceden de los términos del compromiso o de la cláusula compromisoria; no obstante, si las disposiciones de la sentencia que se refieren a las cuestiones sometidas al arbitraje pueden separarse de las que no han sido sometidas al arbitraje, se podrá dar reconocimiento y ejecución a las primeras; o

d) Que la constitución del Tribunal Arbitral o el procedimiento arbitral no se han ajustado al acuerdo celebrado entre las partes o, en defecto de tal acuerdo, que la constitución del Tribunal Arbitral o el procedimiento arbitral no se han ajustado a la ley del país donde se ha efectuado el arbitraje; o

e) Que la sentencia no es aún obligatoria para las partes o ha sido anulada o suspendida por una autoridad competente del país en que, o conforme a cuya ley, ha sido dictada esa sentencia. 
York hacemos referencia a la causal prevista en el inciso b del artículo V, inciso según el cual se podrá denegar el reconocimiento si "la parte contra la cual se invoca la sentencia arbitral no ha sido debidamente notificada de la designación del árbitro o del procedimiento de arbitraje o no ha podido, por cualquier otra razón, hacer valer sus medios de defensa".

La facultad de los jueces para rechazar la ejecución de un laudo encuentra sustento en tres aspectos delimitados por la Convención. El primero de ellos es que se demuestre que la parte vencida en el arbitraje no tuvo la oportunidad de conocer sobre la designación del árbitro o de los árbitros conformantes del Tribunal Arbitral, y es que no conocer oportunamente sobre la designación del árbitro o los árbitros puede limitar el acceso de información relevante para alguna de las partes sobre el posible desempeño de aquellos en el proceso arbitral, pues los árbitros podrían tener, en el caso concreto, algún tipo de interés referido a: la materia controvertida; alguna de las partes; o alguno de los árbitros. Estos aspectos, si no son conocidos de manera oportuna, pueden colocar a alguna de las partes en situación de desventaja frente a la otra.

Un segundo aspecto está circunscrito a no haber conocido o no haber sido notificado de alguna decisión o escrito dentro del proceso arbitral. De hecho, la ocurrencia de este incidente deja claramente a la parte no notificada en una situación de desventaja en el proceso arbitral, pues al no haber tenido la oportunidad de conocer $\mathrm{y}$, por ende, manifestar su opinión respecto a lo decidido por el Tribunal o a lo argumentado por la otra parte, sus posibilidades de éxito podrían verse diezmadas.

Este segundo aspecto encuentra relación directa con el tercero: que una de las partes no haya podido hacer valer sus medios de defensa. $Y$

2. También se podrá denegar el reconocimiento y la ejecución de una sentencia arbitral si la autoridad competente del país en que se pide el reconocimiento y la ejecución, comprueba:

a) Que, según la ley de ese país, el objeto de la diferencia no es susceptible de solución por vía de arbitraje; o

b) Que el reconocimiento o la ejecución de la sentencia serían contrarios al orden público de ese país. 
es que la no notificación oportuna acarrea la vulneración del derecho de la parte a cuestionar la decisión o a rebatir los argumentos de su contraparte, situación que, en un escenario de conflicto, agrava la relación no solo con la parte contraria, sino con los árbitros y, con ello, el propio proceso arbitral.

Entramos, así, a un campo que si bien la Convención de Nueva York no aborda, resulta de vital importancia tener en cuenta, dado que el sustento o la verificación de dicha vulneración acarrea de plano la denegatoria en la ejecución del laudo.

Sobre este particular, si bien la Convención fue aprobada antes de la creación de la Comisión de Naciones Unidas para el Derecho Mercantil Internacional (Cnudmi) - Uncitral, en inglés -, esta última adoptó, en 1996, unas notas sobre la organización del proceso arbitral que buscan coadyuvar en la solución ordenada del conflicto de carácter internacional, indicando la necesidad de resolver temas importantes, no solo referidos al idioma o lugar de las actuaciones arbitrales señaladas en la convención, sino a otros muchos aspectos, como la confidencialidad de las actuaciones, la práctica de la prueba, el oír a las partes, etc. Hay que manifestar que estas notas no tienen un carácter imperativo para los tribunales arbitrales; significan, más bien, una guía de la que pueden valerse los árbitros en el momento de enfrentar un proceso arbitral.

\section{Debido proceso}

El criterio general aceptado universalmente es el criterio de la libertad de las partes para elegir el procedimiento; en defecto de esta elección, la gran mayoría de legislaciones permiten que los árbitros elijan el procedimiento, a pesar de que algunas consideran de orden público interno la aplicación de las reglas procesales del lugar de la sede del tribunal arbitral o árbitro único.

En caso de que sean los árbitros quienes señalen el procedimiento en defecto de la voluntad de las partes (sea porque estas no lo indicaron en el convenio arbitral o no se sujetaron a las reglas de alguna institución permanente de arbitraje o a reglas determinadas), y en la medida en que la ley interna del país sede así lo permita, los árbitros deberán fijar las reglas procedimentales con anterioridad a la iniciación del procedimiento. 
Estas precisiones pueden realizarse de manera unilateral o previa consulta con las partes $\mathrm{o}$, incluso, en un acto simultáneo donde se encuentren tanto árbitros como partes invitadas por estos.

La nota 9 de la Cnudmi señala, sobre este tema:

En algunos arbitrajes puede dedicarse una sesión especial exclusivamente a esas consultas de procedimiento; otra posibilidad será la de celebrar esas consultas en combinación con una vista sobre el fondo de la controversia. La práctica difiere en cuanto si conviene organizar esas reuniones especiales y la forma de hacerlo. Las reuniones especiales de los árbitros y de las partes celebradas sobre cuestiones de procedimiento, de las vistas o audiencias, son conocidas en la práctica por términos tan diversos como "reuniones preliminares", "conferencia previa a la vista", "conferencia preparatoria", "examen previo a la vista", o por términos de significado análogo. Los términos utilizados dependen, en parte, de la etapa del procedimiento en que se celebre la reunión.

Esta nota plantea la posibilidad de que las reglas de procedimiento sean diseñadas por los árbitros y que las partes puedan intervenir en ese diseño, aunque a estas les deja una actuación secundaria o más bien como espectadoras de las reglas de procedimiento diseñadas por los árbitros.

Y es que, en el escenario internacional, la mayoría de contratos remiten la solución de una controversia al ámbito de aplicación de una institución arbitral y, con ello, a las reglas de procedimiento establecidas en su reglamento. Esta costumbre, si bien ahorra esfuerzo en el diseño de las reglas, puede generar una distorsión en su prosecución, en la medida en que las reglas de una institución arbitral tienden a ser reglas estándares o estandarizadas que, en mayor o menor medida, pueden diferir de las necesidades procesales que un caso concreto amerita.

Bien se sabe que una de las grandes ventajas del arbitraje está dada por la posibilidad de que las partes puedan diseñar reglas de procedimiento acordes a la naturaleza del conflicto, reglas a la medida que les permitan brindarse, ellas mismas, la solución al conflicto según sus expectativas. Es evidente que quienes se encuentran en mejor 
situación para saber cuál es el mejor traje para su controversia son los propios actores.

Las partes son, pues, las llamadas a establecer el diseño de las reglas de procedimiento a fin de procurar una solución rápida, eficiente y completa; o, en todo caso, a establecer - en un escenario de reglas institucionales - qué tipo de reglas son lo suficientemente idóneas para ser aplicadas al conflicto que se desea solucionar, pudiendo incluso disponerse reglas particulares para situaciones específicas.

No obstante, una vez fijadas las reglas de procedimiento o la normativa aplicable a este, se suelen delegar a los árbitros facultades discrecionales para hacer posible la adecuada conducción del proceso arbitral. Este margen de actuación permite que ellos puedan adoptar decisiones respecto al propio procedimiento tomando en cuenta las circunstancias de cada caso, con la única finalidad de resolver el conflicto de manera oportuna, idónea, habiéndoles brindado a las partes la misma oportunidad para hacer valer sus derechos.

De acuerdo con lo señalado por la regla comentada, resulta adecuado propiciar reuniones previas para definir las reglas del procedimiento. En estas reuniones, las partes, junto con los árbitros, podrán establecer de manera clara cuál será la forma de conducción del proceso, fijando además los parámetros para las actuaciones discrecionales de los árbitros y sus alcances, ya que, en materia internacional, suele ocurrir que cada árbitro tiene una forma distinta de conducir el arbitraje, atendiendo a su realidad. Con ello, los alcances de su discrecionalidad pueden estar en rangos y límites distintos, lo que hace necesaria su uniformización.

En otras palabras, tratándose, sobre todo, de arbitrajes internacionales, la discrecionalidad y flexibilidad otorgadas a los árbitros hacen sumamente aconsejable que se lleven a cabo estas reuniones preliminares con las partes a fin de comunicarles la forma en que aquellos van a conducir el proceso. No llevar a cabo estas reuniones podría provocar que algunos aspectos del procedimiento tuvieran un impacto negativo para las propias partes, tanto en la preparación de su defensa como en la percepción de la conducción del arbitraje, perturbando el normal desenvolvimiento de los árbitros y ocasionando con ello demoras y costos que pudieron preverse.

En ese orden de ideas, consideramos que, a fin de evitar la vulneración del derecho de defensa de una de las partes o de no crear algún tipo de 
distanciamiento entre estas y el Tribunal Arbitral, los árbitros deberán establecer claramente la mecánica procesal con anterioridad al procedimiento y ponerla en conocimiento de las partes, dificultando de esa manera posibles cuestionamientos.

Claro está que si las partes no manifiestan absolutamente nada respecto a la mecánica procesal, se entenderá que hacen suyas dichas reglas y no podrán cuestionarlas durante la tramitación del proceso.

Por otro lado, se debe considerar que en estas reuniones preliminares puede escabullirse alguna regla en particular, ya sea porque las partes y los árbitros centraron su discusión en algún otro aspecto del procedimiento, dejando de lado aquel, o porque, simplemente, tanto los árbitros como las partes obviaron dicha regla por considerarla "de mero trámite".

$\mathrm{Al}$ respecto, tratándose de reglas de procedimiento, importa recalcar que ninguna regla es de mero trámite. Las reglas del proceso arbitral son un conjunto de disposiciones que se engranan formando un todo -el proceso arbitral $-\mathrm{y}$, por ende, ninguna regla debe dejarse al azar o sin discutir. Todas y cada una de las normas procesales aplicables a un arbitraje deben pasar por un tamiz reflexivo que importe la discusión sobre las posibles consecuencias que generarán en el desarrollo del proceso y, en estricto, la solución del conflicto.

Sin embargo, puede ocurrir que, a pesar de las reuniones preliminares, los árbitros y las partes no hayan previsto todas las figuras procesales aplicables. Ante ello, es recomendable que el Tribunal Arbitral deje expresa reserva de la creación de normas especiales con la finalidad de suplir cualquier vacío en las reglas de procedimiento, puesto que la no reserva podría importar, nuevamente, el estancamiento del proceso o, peor aún, su cuestionamiento por aquella parte que siente que - según las actuaciones arbitrales - no estaba prevista tal conducta y, por tal motivo, considera vulnerada la equidad del proceso.

\section{Acta de instalación}

En el Perú utilizamos la figura del "acta de instalación" para fijar las reglas de procedimiento arbitral, en donde los árbitros, por lo general, invitan a las partes a efectos de exponerles el texto trabajado por ellos y las características del desarrollo procedimental, además de temas operativos como horario para presentar documentos, días hábiles del proceso, copias necesarias que se deben adjuntar, idioma, traducción de documentos, cos- 
tos de traducción en caso de que lo solicite el tribunal, notificaciones vía electrónica, presentación de demandas simultaneas, plazos, ley aplicable para resolver el fondo de la controversia, entre otros. ${ }^{2}$

La invitación a las partes a la audiencia de instalación es un paso importante para el desarrollo adecuado - desde el punto de vista procesal - de todo arbitraje, en razón de que su aceptación de las reglas propuestas por los árbitros será la única posibilidad de que estas puedan ser utilizadas en el proceso. Su no conformidad producirá dos efectos: que los árbitros modifiquen la regla según la conveniencia de las partes o que no asuman la función de arbitrar.

En ese sentido, la discrecionalidad de los árbitros en el diseño y elección de las reglas del proceso puede haberse pactado por las partes, sea en forma directa o mediante la aceptación de las reglas propuestas por los árbitros, pero siempre será la potestad de aquellas la que prime sobre la voluntad de estos en el momento de diseñar las reglas de procedimiento.

Otra posibilidad es que las partes se rijan por las reglas de un reglamento arbitral al cual se hayan sometido, o por el derecho interno aplicable al arbitraje. En este aspecto, será el propio reglamento el que fije las pautas procedimentales para el desarrollo del arbitraje, pudiendo las partes establecer, incluso en estos casos, las condiciones por las que el reglamento al que se han sometido será de aplicación al proceso arbitral

Vemos, pues, en cuanto a las reglas del procedimiento, que son las propias partes las que de manera previa, en la cláusula compromisoria, o de manera posterior, mediante un acuerdo - por lo general, en el acta de instalación-, determinan su aplicación.

\section{Inciso $\mathrm{d}$ del artículo $\mathrm{V}$}

Otro aspecto es el recogido por el inciso d del artículo V de la Convención de Nueva York, que admite como fundamento para la denegatoria:

2 Nótese que, en la mayoría de los casos, las reglas del procedimiento se encuentran plasmadas en un documento de trabajo elaborado por los propios árbitros, lo cual no quiere decir que las reglas que regirán el proceso sean de estos, pues para que puedan entrar en vigencia en un determinado proceso se necesitará el acuerdo de las partes. 
"Que la constitución del Tribunal Arbitral o el procedimiento arbitral no se han ajustado al acuerdo celebrado entre las partes o, en defecto de tal acuerdo, que la constitución del Tribunal Arbitral o el procedimiento arbitral no se han ajustado a la ley del país donde se ha efectuado el arbitraje $[\ldots]^{\prime \prime}$.

Al igual que en el punto comentado anteriormente, tanto la constitución del Tribunal Arbitral como las reglas de procedimiento utilizadas por los árbitros en la conducción del proceso deben estar acordes con la manifestación de voluntad de las partes.

En cuanto al primer punto, si es que en el convenio arbitral las partes han acordado una forma de designación de árbitros, se deberá respetar dicho acuerdo. Lo mismo sucede con las reglas del proceso: ya se ha comentado que las reglas de procedimiento son de las partes, y, en defecto de estas, son los árbitros los que las proponen, pero serán las partes las que en última instancia acepten o decidan modificar dichas reglas. En consecuencia, actuar en contra de las reglas de procedimiento (o desconociéndolas) establecidas por las partes, o aceptadas por estas, genera un grave vicio en la decisión final (laudo) y, por tanto, el juez, una vez verificado aquello, denegará su ejecución.

En lo atinente a la ley del país donde se ha efectuado el arbitraje, la denegatoria en la ejecución de los laudos respecto a este punto resulta, al parecer, de una mera revisión de la legislación interna para saber si un laudo puede o no ejecutarse en dicho país. Ello podría ser así hasta que nos encontramos con el complejo concepto del orden público internacional. En efecto, no es extraño que la gran mayoría de partes que son vencidas en un proceso arbitral utilicen esta causal para procurar impedir la ejecución del laudo, pues la definición de orden público resulta ser una delimitación bastante compleja de establecer.

\section{Orden público interno e internacional}

La doctrina comparada hace referencia tanto al orden público del derecho interno como al orden público internacional (este último, con una noción más restringida que la primera). Según lo manifestado por J. Jitta, pueden establecerse dos criterios cuando se habla de orden público: uno amplio y uno más bien restringido. Con relación al primer criterio, señala: 
[...] en el derecho privado nacional está interesado el orden público de todas las instituciones jurídicas que la ley no abandona a la voluntad de los particulares; el estado de las personas es, en este sentido, de orden público y por eso los particulares no pueden determinar, mediante un contrato, que su matrimonio haya de ser indisoluble o disoluble por bajo condiciones distintas a las condiciones legales [...]. Pero en el derecho internacional privado, el principio de orden público no se presenta de ese modo, o con esa amplitud, cuyo efecto sería la paralización de la vida internacional: hay que tomar, pues, la frase orden público, dentro de una ciencia en sentido menos amplio, por más que cuando se trata de precisar sea difícil entenderse. La gran dificultad para llegar a una conclusión, precisa y universalmente aplicable, a la vez, consiste en la necesidad de limitar su aplicación a las leyes extranjeras. Al juez no le corresponde examinar si sus leyes son contrarias a los órdenes públicos o hasta inmorales, sino que les debe obediencia aunque en su fuero interno las juzgue antisociales e inmorales en el más alto grado. El juez sólo puede criticar las leyes extranjeras, y aun en esta crítica no puede abandonarse libremente a su inspiración (s/f: 178 ss.).

Por su parte, Niboyet - al comentar lo manifestado por Pillet sobre el orden público - sostiene que "las leyes de orden público son las que deben ser generales para que no dejen de cumplir su objeto social. Luego, entre la idea de orden público y la de generalidad existe una verdadera e indivisible relación" (1957: 399)

Dicho esto, el orden público que debe sustentarse como causal de nulidad o de no ejecución de un laudo es el destinado a evitar la aplicación en el ordenamiento interno de un país, de una institución ofensiva a, o que se contrapone con, las instituciones jurídicas que ese país considera importantes.

Así las cosas, cualquier sentencia arbitral (laudo) dictada en ausencia de una de las partes o en un procedimiento arbitral en el que no se notificó la designación del árbitro o la iniciación del proceso o se hizo en forma defectuosa y que prive a las partes de su legítimo derecho para recusar a un árbitro; la falta de notificación sobre el inicio del proceso que impida a la parte afectada salir a juicio para exponer su caso y ejercitar su defensa; así como la vulneración del orden público consagrado en lo dispuesto por la ley del país donde se pretenda ejecutar un laudo, 
son causales y razones suficientes para solicitar la denegatoria del reconocimiento de la decisión a la cual afectan.

El orden público es, pues, un criterio que debe analizarse al momento en que las partes establecen las reglas de procedimiento, en particular, el lugar del arbitraje. Y no solo atendiendo la ley del lugar en torno al procedimiento arbitral, sino en torno a la ejecución del laudo. Y quizá verificando la existencia de un tratado entre el Estado donde se llevará el arbitraje y aquel donde el laudo deba ejecutarse. 


\section{Bibliografía}

JITTA, J. (s/f) Método de derecho internacional privado. Madrid: SNE Editores/ La España Moderna.

MANTILLA-SERRANO, Fernando. (2009). "Algunos apuntes sobre la ejecución de los laudos anulados y la Convención de Nueva York". International Law, Revista Colombiana de Derecho Internacional 15.

NIBOYET, J.P. (1957). Principios de derecho internacional privado. 2. ${ }^{a}$ edición. México: Editora Nacional. 